\title{
The role of community pharmacists in immunisation: a national cross-sectional study
}

\author{
Nikolaus Lindner ${ }^{1}\left(\mathbb{D} \cdot\right.$ Martin Riesenhuber $^{2}$ (]) $\cdot$ Thomas Müller-Uri $^{3} \cdot$ Anita Elaine Weidmann $^{4}$ ()
}

Received: 2 September 2021 / Accepted: 15 November 2021 / Published online: 26 November 2021

(c) The Author(s) 2021

\begin{abstract}
Background Austrian pharmacists are not authorised to administer immunisations, and evidence about their willingness to immunise is lacking. Aim The aim of this study is to investigate Austrian community pharmacists' willingness to administer immunisations in the future. Method This study is designed as a cross-sectional online survey based on the theoretical domains framework (TDF). The validated and piloted questionnaire obtained ethical approval by Robert Gordon University. Outcome measures included pharmacists' willingness to immunise, service requirements, barriers and education needs. Results The questionnaire was sent out to 3086 community pharmacists of which 380 responses were included in the final analysis (12.3\%). Willingness to administer immunisations after appropriate training and legislative regulation was stated by $82.6 \%$ ( $n=314$ ) of participants. It was demonstrated that pharmacists willing to immunise were significantly younger than their counterpart (38 [IQR 31-49] years vs. 45 [IQR 37.5-54] years; OR 1.06; 1.03-1.09, 95\% CI; $p<0.001$ ). 'Legal liability' was considered the most critical barrier to service implementation, 'seeing blood' and 'close patient contact' as least critical. Pharmacists not willing to immunise showed a higher probability to evaluate personnel resources (OR 2.98; $1.35-6.58,95 \% \mathrm{CI} ; p=0.007$ ), close patient contact (OR 2.79; $1.46-5.34,95 \% \mathrm{CI} ; p=0.002$ ) and management of side effects (OR $2.62 ; 1.21-5.67,95 \% \mathrm{CI} ; p=0.015$ ) as (highly) critical. The majority assessed the 'right timing for training' to be after the foundation training with a 2-yearly renewal. Conclusion Austrian community pharmacists show a strong willingness to administer immunisations while highlighting important requirements and barriers towards service implementation.
\end{abstract}

Keywords Community pharmacy $\cdot$ Covid $\cdot$ Pharmacist immunisation $\cdot$ Questionnaire $\cdot$ Service implementation $\cdot$ Survey . Vaccine

\section{Impact on Practice}

- Austrian community pharmacists are not authorised to immunise, but report a high willingness to administer vaccines in the future.

Nikolaus Lindner

lindnerniko@gmail.com

1 School of Pharmacy and Life Sciences, Robert Gordon University, Garthdee Road, Aberdeen AB10 7QB, Scotland, UK

2 Division of Cardiology, Department of Internal Medicine II, Medical University of Vienna, Vienna, Austria

3 Vindobona-Apotheke, Community Pharmacy, Vienna, Austria

4 Faculty of Chemistry and Pharmacy, University of Innsbruck, Innsbruck, Austria
- This study serves as a valuable instrument for stakeholders attempting to implement a pharmacist provided immunisation-service.

- Legalisation of vaccine administration will enable pharmacists to take on a patient-centred role in the Austrian health care system.

- Pharmacist provided immunisation-services will facilitate access to vaccines for patients.

\section{Introduction}

According to the World Health Organisation (WHO), immunisations in general prevent 2-3 million deaths each year across all age groups [1]. Vaccines themselves represent a successful and cost-effective measure to combat numerous infectious diseases of varying severity. To improve access to vaccinations, many countries have 
already expanded the role of pharmacists from immunisation educators to active immunisers in the community setting [2]. Alongside big healthcare systems such as Canada, USA and Australia, several European countries such as the United Kingdom, France and Portugal have introduced pharmacist-provided immunisation services [3]. A meta-analysis from Baroy et al. investigated pharmacist-provided vaccination services in the USA in 5 community sites and 3 hospitals including 11 study arms [4]. An increase in overall immunisation rates delivered by pharmacists' immunisation programmes was shown compared to usual care $(\mathrm{RR}=2.95, p<0.001)$ and varied based on the type of vaccine with the highest risk ratio for the herpes vaccine subgroup ( $\mathrm{RR}=4.78, p<0.001)$, and the smallest for the flu vaccine subgroup $(R R=2.23$, $p<0.001)$. Isenor et al. performed a pooled analysis of two randomised controlled trials examining pharmacistprovided immunisation services in the USA [5]. This analysis demonstrated a significant increase in overall immunisation rates compared to normal immunisation service provision $(\mathrm{RR}=2.64,1.81-3.86,95 \% \mathrm{CI})$. A more recent systematic review by Spinks et al. from 2020 further suggests that pharmacist-provided vaccinations may additionally result in reduced costs and improved convenience [6]. While these settings are not directly comparable to the Austrian health care system, the Austrian Chamber of Pharmacists maintains that community pharmacists remain the most easily accessible health care professional with 95\% of the Austrian public able to reach a community pharmacy within 10 min [7]. Up to now, Austrian community pharmacists' willingness towards administering vaccines remains unexplored. In Austria, only physicians and nurses under the supervision of a physician are authorised by law to administer immunisations. The threat of the emerging Covid-19 pandemic and expected low flu immunisation rates resulted in a proposal of a pharmacistprovided immunisation service in early 2020 . While this aimed at providing a valuable strategy to improve access to vaccination services across the general public, it has caused controversial discussions among stakeholders. Austrian community pharmacists are advocating for the introduction of pharmacist-provided immunisation services not only to accelerate Covid-19 vaccination coverage, but also to combat low flu immunisation rates and increasing tick borne encephalitis cases $[8,9]$. However, proposals are confronted with safety concerns by medical stakeholders and opposing political parties $[10,11]$.

In light of the ongoing Covid-19 pandemic it is essential to quickly increase immunisation uptake to possibly attain herd immunity and prevent further disease outbreaks, while also maintaining general and flu vaccination coverage. A potent strategy to increase vaccination uptake is to improve access to vaccination services [12].

\section{Aim}

The aim of this study is to investigate Austrian community pharmacists' willingness to administer immunisations in the future.

\section{Ethics approval}

Ethical approval for the study was obtained by the School Research Ethics Committee of Robert Gordon University, Aberdeen on the 7th December 2020. The Ethics Committee of the City of Vienna advised that no further ethical approval was needed.

\section{Method}

\section{Study design and data collection tool development}

This study is a cross-sectional online survey that was designed using Jisc 'online surveys' (https://www.onlin esurveys.ac.uk/). Primary outcomes included the percentage of employed Austrian community pharmacists willing to administer immunisations, a ranking of relevant requirements and barriers to implementation of an immunisation service and desired training specifications. Secondary outcomes included matters brought up in the open-response section of the questionnaire. The questionnaire was based on best practice guidelines and the Theoretical Domains Framework (TDF), an integrative framework validated as a method 'for theoretically assessing implementation problems' [13-15]. The following domains of the TDF were addressed in the study: skills, professional role and identity (section 1); beliefs about capabilities, intentions, goals, environmental context and resources, social influences (section 2); goals (section 3). Answer options consisted of open/closed questions, Likert-scale and semantic differential questions.

Participating pharmacists were provided assurance of anonymity in the invitation E-mail, the information leaflet and at the beginning of the questionnaire in line with the British Psychological Society's Ethics Guidelines for Internet-mediated Research [16]. The survey with all corresponding materials (information leaflet, email covering note) was pretested for face and content validity among five research experienced pharmacy practitioners. The questionnaire was adapted according to feedback on survey design and content appropriateness. Piloting was carried out in 36 Austrian pharmacists ( $10 \%$ of final sample size). Feedback from 21 responding participants (response 
rate: $58.3 \%$ ) as well as technical issues and trends in (non)responses were analysed and the questionnaire was modified accordingly. Responses of the pilot were not included in the final analysis.

\section{Study population and sample size}

A sample size calculation was performed based on all registered employed community pharmacists in Austria $(n=4575)$. A margin of error of $5 \%$ and a confidence level of $95 \%$ were considered as adequate for statistical analysis. This resulted in a sample size of 355 pharmacists. The questionnaire was distributed by the Austrian Association of Employed Pharmacists (VAAÖ) and Forum Pharmazie Vienna to all its members for whom email addresses were available $(n=3086)$. Pharmacists who were retired, nonGerman speaking or not working in community pharmacy were excluded. One reminder email was sent after one week. Data was collected over a period of 5 weeks between 19th January 2021 and 23rd February 2021.

\section{Data analysis}

Statistical analysis was performed using SPSS (vs 21.0) and included descriptive statistics, cross-tabulations, relevant parametric/non-parametric tests and regression analyses. Continuous variables were tested for normal distribution by Kolmogorov-Smirnov test. For normal distributed continuous variables, means \pm standard deviations were calculated. For non-normal distributed continuous variables, medians \pm interquartile ranges (IQR) were calculated. Groups with continuous variables were compared with the t-test (normal distribution) or with the Mann-Whitney U test (non-normal distribution). Discrete variables were compared with the chi-square test. Odds ratios were calculated with a logistic regression model, and 95\% confidence intervals were reported. Parameters were included in the multifactorial regression if the $\mathrm{p}$ value was $<0.1$ in the univariate regression model. A two-sided $p$ value $<0.05$ was considered statistically significant.

\section{Results}

\section{Response rate}

Out of 433 respondents, 46 (10.6\%) were excluded for being hospital pharmacists, and 7 (1.6\%) were excluded for working in other fields of practice. In total, 380 community pharmacists (87.8\%) were included in the final analysis, which results in a response rate of $12.3 \%$. This represents $8.3 \%$ of all employed community pharmacists $(n=4575)$ in Austria and meets the calculated sample size expectation [7].
Previous studies distributed to Austrian community pharmacists reported response rates of approximately 3-19.1\% $[17,18]$.

\section{Socio-demographic characteristics}

Detailed participant characteristics stratified by willingness to immunise are displayed in Table 1 . Out of a total sample of 380 participants, $341(89.7 \%)$ were female. This is representative of the demographics of community pharmacists in Austria, where $86.7 \%(n=3967)$ of all employed community pharmacists are female [7]. Participants' median age was 40 [IQR 32-50] years with a median work experience of 12 [IQR 4-22] years. The majority of participants were pharmacists that worked in pharmacies with 5-10 employees $(n=162 ; 42.6 \%)$ or in pharmacies with 11-20 employees $(n=172 ; 45.3 \%)$.

\section{Willingness to immunise}

In total, 314 of 380 community pharmacists $(82.6 \%)$ expressed willingness to administer immunisations after appropriate training and legislative regulation (Table 1). Regression analysis showed that pharmacists willing to immunise were significantly younger than pharmacists not willing to immunise (38 [IQR 31-49] years vs. 45 [IQR 37.5-54] years; OR 1.06, 95\% CI 1.03-1.09, p <0.001). No statistically significant difference was seen across genders. In relation to patient groups that pharmacists would administer vaccines to, all pharmacists are willing to immunise adults from 18 to 65 years $(n=314,100.0 \%)$, whereas only $15.6 \%(n=49)$ of participants would administer vaccines to children under 14 years of age (Table 2). Vaccine types that pharmacists are willing to administer are displayed in Table 3.

\section{Requirements for service implementation}

The majority of participants regarded 'appropriate training' ( $n=336,88.4 \%)$, 'liability insurance' $(n=297,78.2 \%)$ and 'acceptance by patients' $(n=280,73.7 \%)$ as highly important (Table 4). 'Acceptance by physicians' and 'financial remuneration' were considered as less important, with only $39.2 \%(n=149)$ and $30.8 \%(n=117)$ of participants rating these aspects as highly important. In the open comments, participants added that further important requirements include 'adequate pharmacy premises', 'acceptance by politics and stakeholders', 'legal implementation' and 'appropriate training incorporating first-aid measures'. One pharmacist pointed out that 'future legal regulation and solid education will act as proof that pharmacists are equally qualified to vaccinate compared to other healthcare professionals' [P-71247183]. 
Table 1 Collective participant characteristics stratified by willingness to immunise

\begin{tabular}{|c|c|c|c|c|}
\hline & Total & Willing to immunise & Not willing to immunise & $p$ value \\
\hline Total sample $-n(\%)$ & $380(100.0 \%)$ & $314(82.6 \%)$ & $66(17.4 \%)$ & \\
\hline Age (years) - median [IQR] & $40[32-50]$ & 38 [31-49] & $45[37.5-54]$ & $<0.001 *$ \\
\hline Work experience (years) - median [IQR] & $12[4-22]$ & $10[4-20]$ & $20[10.5-25]$ & $<0.001 *$ \\
\hline \multicolumn{5}{|l|}{$\operatorname{Sex}-n(\%)$} \\
\hline Female & $341(89.7 \%)$ & $280(89.2 \%)$ & $61(92.4 \%)$ & \multirow[t]{3}{*}{$0.048 * *$} \\
\hline Male & $38(10.0 \%)$ & $34(10.8 \%)$ & $4(6.1 \%)$ & \\
\hline Not specified & $1(0.3 \%)$ & $0(0.0 \%)$ & $1(1.5 \%)$ & \\
\hline \multicolumn{5}{|l|}{ Level of education- $n(\%)$} \\
\hline Mag. pharm. & $350(92.1 \%)$ & $291(92.7 \%)$ & $59(89.4 \%)$ & \multirow[t]{4}{*}{$0.706 * *$} \\
\hline Dr./PhD & $26(6.8 \%)$ & $20(6.4 \%)$ & $6(9.1 \%)$ & \\
\hline Other & $1(0.3 \%)$ & $1(0.3 \%)$ & $0(0.0 \%)$ & \\
\hline Not specified & $3(0.8 \%)$ & $2(0.6 \%)$ & $1(1.5 \%)$ & \\
\hline \multicolumn{5}{|l|}{ Postgraduate degree-n (\%) } \\
\hline Yes & $56(14.7 \%)$ & $48(15.3 \%)$ & $8(12.1 \%)$ & \multirow[t]{3}{*}{$0.218^{*}$} \\
\hline No & $309(81.3 \%)$ & $256(81.5 \%)$ & $53(80.3 \%)$ & \\
\hline Not specified & $15(3.9 \%)$ & $10(3.2 \%)$ & $5(7.6 \%)$ & \\
\hline \multicolumn{5}{|l|}{ Immunisation counselling-n $(\%)$} \\
\hline Yes & $364(95.8 \%)$ & $303(96.5 \%)$ & $61(92.4 \%)$ & \multirow[t]{2}{*}{$0.134 *$} \\
\hline No & $16(4.2 \%)$ & $11(3.5 \%)$ & $5(7.6 \%)$ & \\
\hline \multicolumn{5}{|l|}{ Workplace (employees)—n(\%) } \\
\hline$<5$ employees & $9(2.4 \%)$ & $7(2.2 \%)$ & $2(3.0 \%)$ & \multirow[t]{5}{*}{$0.003^{*}$} \\
\hline 5-10 employees & $162(42.6 \%)$ & $130(41.4 \%)$ & $32(48.5 \%)$ & \\
\hline 11-20 employees & $172(45.3 \%)$ & $148(47.1 \%)$ & $24(36.4 \%)$ & \\
\hline$>20$ employees & $32(8.4 \%)$ & $28(8.9 \%)$ & $4(6.1 \%)$ & \\
\hline Not specified & $5(1.3 \%)$ & $1(0.3 \%)$ & $4(6.1 \%)$ & \\
\hline \multicolumn{5}{|l|}{ Workplace (inhabitants)—n (\%) } \\
\hline$<1.000$ inhabitants & $2(0.5 \%)$ & $1(0.3 \%)$ & $1(1.5 \%)$ & \multirow[t]{7}{*}{$0.031 *$} \\
\hline $1.000-9.999$ inhabitants & $135(35.5 \%)$ & $106(33.8 \%)$ & $29(43.9 \%)$ & \\
\hline 10.000-49.999 inhabitants & $56(14.7 \%)$ & $49(15.6 \%)$ & $7(10.6 \%)$ & \\
\hline 50.000-99.999 inhabitants & $15(3.9 \%)$ & $15(4.8 \%)$ & $0(0.0 \%)$ & \\
\hline 100.000-499.999 inhabitants & $44(11.6 \%)$ & $37(11.8 \%)$ & $7(10.6 \%)$ & \\
\hline$>500.000$ inhabitants & $123(32.4 \%)$ & $104(33.1 \%)$ & $19(28.8 \%)$ & \\
\hline Not specified & $5(1.3 \%)$ & $2(0.6 \%)$ & $3(4.5 \%)$ & \\
\hline
\end{tabular}

*Mann-Whitney U test, **Chi-square test

Table 2 Patient groups pharmacists are willing to immunise $(n=314)$

\begin{tabular}{llr}
\hline Patient groups & $n$ & $\%$ \\
\hline Adults (18-65 years) & 314 & 100.0 \\
Elderly people (over 65 years) & 239 & 76.1 \\
Adolescents (14-17 years) & 174 & 55.4 \\
Children (under 14 years) & 49 & 15.6 \\
Other & 4 & 1.3 \\
\hline
\end{tabular}

\section{Barriers to the administration of immunisations}

'Legal liability' was considered the most important barrier with $54.7 \%(n=208)$ of participants rating this aspect as
Table 3 Vaccine types pharmacists are willing to administer $(n=314)$

\begin{tabular}{lll}
\hline Vaccine types & $n$ & $\%$ \\
\hline Influenza & 302 & 96.2 \\
Tick-borne encephalitis & 298 & 94.9 \\
General vaccinations & 259 & 82.5 \\
Covid-19 & 206 & 65.6 \\
Travel vaccinations & 161 & 51.3 \\
Other & 14 & 4.5 \\
\hline
\end{tabular}

highly critical (Fig. 1). In addition, more than $50 \%$ of the participants regarded the following barriers as highly critical and critical: 'conflict with other healthcare professionals' 
Table 4 Requirements for service implementation $(n=380)$

\begin{tabular}{lllll}
\hline Topic & Highly important & Important & Hardly important & Not important \\
\hline Appropriate training & $88.4 \%(336)$ & $11.3 \%(43)$ & $0.3 \%(1)$ & $0.0 \%(0)$ \\
Liability insurance & $78.2 \%(297)$ & $20.3 \%(77)$ & $1.6 \%(6)$ & $0.0 \%(0)$ \\
Acceptance by patients & $73.7 \%(280)$ & $25.3 \%(96)$ & $0.8 \%(3)$ & $0.3 \%(1)$ \\
Acceptance by physicians & $39.2 \%(149)$ & $39.2 \%(149)$ & $18.2 \%(69)$ & $3.4 \%(13)$ \\
Financial remuneration & $30.8 \%(117)$ & $49.7 \%(189)$ & $18.4 \%(70)$ & $1.1 \%(4)$ \\
\hline
\end{tabular}

Data is displayed as \% (n)
Fig. 1 Pharmacist reported barriers for the administration of immunisations $(n=380)$

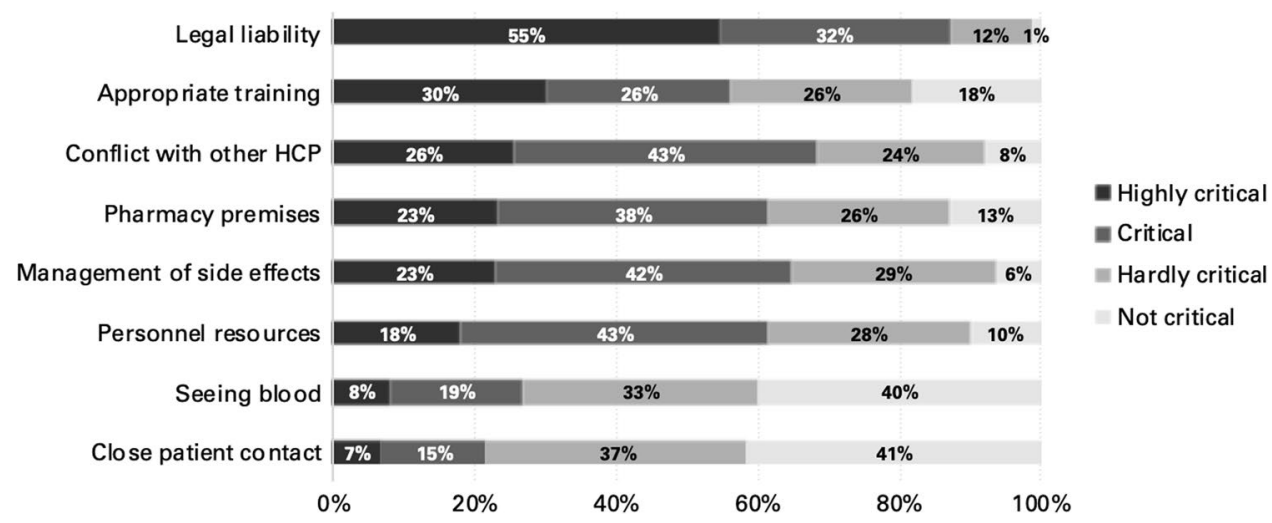

( $n=260,68.4 \%)$, 'management of side effects' $(n=246$, $64.8 \%)$, 'adequate pharmacy premises' ( $n=234,61.6 \%)$, 'personnel resources' $(n=234,61.6 \%)$ and 'appropriate training' $(n=214,56.4 \%)$. The minority of participants rated the 'sight of blood' ( $n=102,26.9 \%)$ and 'close patient contact' $(n=83,21.8 \%)$ as highly critical and critical.

In comparison to pharmacists willing to immunise, pharmacists not willing to immunise more probably rated 'personnel resources' (OR 2.98, 95\% CI 1.35-6.58, $\mathrm{p}=0.007$ ), 'close patient contact' (OR 2.79, 95\% CI 1.46-5.34, $p=0.002)$ and 'management of side effects' (OR 2.62, 95\% CI 1.21-5.67, $p=0.015$ ) as critical/highly critical (Fig. 2). Participants that work in a pharmacy with $\leq 10$ employees more probably rated 'management of side effects' (OR 1.58, 95\% CI 1.03-2.43, $p=0.037$ ) and 'personnel resources' (OR $1.55,95 \%$ CI $1.02-2.36, p=0.042$ ) as critical/highly critical in comparison to participants that work in a pharmacy with more than 10 employees. In contrast to these findings, participants that work in a pharmacy with $\leq 10$ employees less probably rated 'conflict with other HCP' as critical/highly critical (OR 0.65, 95\% CI 0.42-1.00, $p=0.052$ ), albeit not statistically significant.

Additional barriers identified in the free text responses included 'fear of needles', 'acceptance by patients/physicians', 'management of emergencies/side effects' and 'delineation of job profiles for physician and pharmacist'. One pharmacist added that 'physicians and their stakeholders represent an insurmountable hurdle in Austria' [P-70820348]. Another pharmacist pointed out that they ' $d o$ not consider administering vaccinations as a pharmaceutical task' [P-70823562].

\section{Education and training}

The majority of participants prefer training to be held after the foundation training $(n=173,45.5 \%)$ with a 2 -yearly renewal interval $(n=136,35.8 \%)$. Almost all participants regarded 'first aid' $(n=347,91.3 \%)$, 'assessment of indications and contraindications' $(n=345,90.8 \%)$ as well as 'practical administration' $(n=342,90.0 \%)$ as highly relevant topics for the immunisation training programme. Topics such as the 'vaccination schedule', 'preventable diseases', 'travel vaccinations' and '(bio)chemical characteristics' were considered as less relevant. Other important topics specified in the open response options included 'handling of special patient groups', 'communication', 'legal basis', 'logistics', 'hygiene and documentation'. One pharmacist added that 'besides educational documentation it is vital to document and evaluate vaccination uptake after introduction of the pharmacist-provided service' [P-70862523]. Another pharmacist emphasised that 'the communicational aspect of interacting with vaccination sceptics should be included in the training' [P-70850050]. 
Fig. 2 Critical barriers identified by pharmacists not willing to administer immunisations

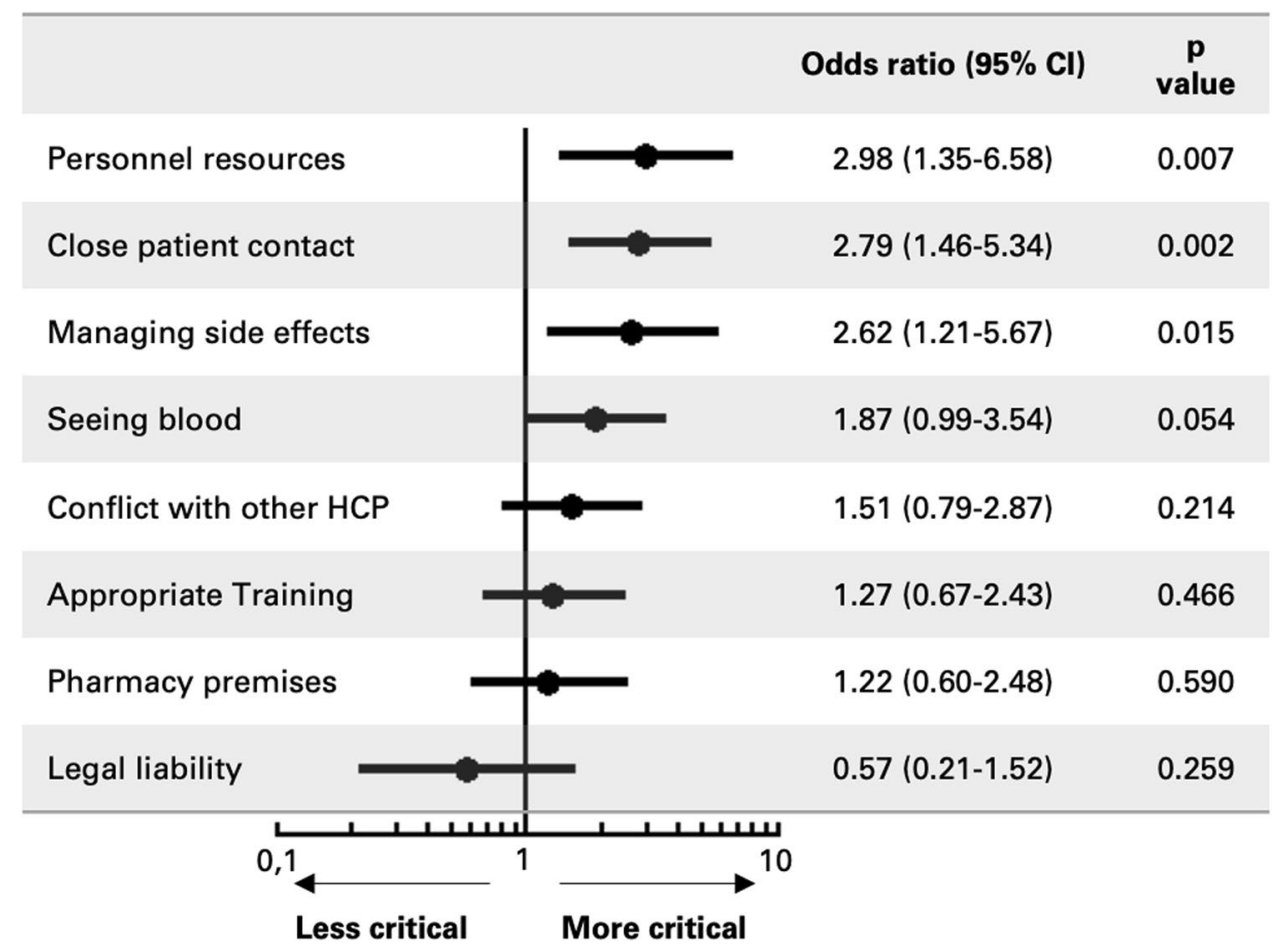

\section{Discussion}

The results presented in this study clearly demonstrate that community pharmacists in Austria show a strong willingness to administer immunisations with $82.6 \%(n=314)$ of respondents being in favour. However, appropriate training, liability insurance and acceptance by patients were considered to be highly important requirements for the successful implementation of a pharmacist-provided immunisation service. This study is the first to explicitly investigate Austrian community pharmacists' willingness to deliver a vaccination service in the future. Despite the reasonably low response rate of $12.3 \%(n=380)$, the study meets its sample size target for the pharmacist population across all of Austria. The gender distribution of study participants is comparable to the latest community pharmacy census study [7]. Major limitations of the study lie in its nature of a questionnaire study and may have resulted in a potential (non-) response and selection bias. The questionnaire was not distributed to the whole population of 4575 Austrian employed community pharmacists, however to a sample of 3086 pharmacists (67.5\%). Reasons for this restricted distribution were institutional policies by the Austrian Chamber of Pharmacists. This limitation may lead to a potential selection bias. Moreover, it cannot be excluded that the questionnaire was distributed to other pharmacists that are not members of the distributing associations. However, through the survey design it was assured that only non-retired, German speaking community pharmacists have been selected for the final analysis.
Another limitation is the sole representation of the pharmacists' perspective. The attitude of other healthcare professionals, patients and policy makers towards implementation of a pharmacist-provided immunisation service should be addressed in further work as they can act as limiting factors upon and after implementation of such a service.

In 2015, Edwards et al. also reported an overwhelming willingness of community pharmacists in Canada (68.0\%, $n=337$ ) to administer immunisations [19]. However, a high number of respondents $(43.0 \%, n=213)$ were pharmacy owners or managers. Their attitudes can differ from those of employed community pharmacists possibly due to their age and economic orientation. Moreover, a potential response bias may have been incurred in our study as a consequence of the current national debate around pharmacists' ability to immunise in Austria. These circumstances may have led to a substantially higher percentage of Austrian community pharmacists willing to administer immunisations. However, the current debate does not only raise heated discussions between the medical and pharmacist associations, but also among pharmacists themselves, with some considering immunising as a 'non-pharmaceutical task' in the open comments. Our study further demonstrates that Austrian community pharmacists willing to immunise are significantly younger than their counterpart. This can probably be explained by the changing role of pharmacists in the health care system from a drug-focused role to a more patient-facing role [20]. Following examples of the Anglo-American region and political pressure in the last 20 years, Austrian 
pharmacy schools have included selected clinical pharmacy topics into their undergraduate curricula and have started to offer post-graduate education opportunities to meet the demands of a modern pharmacist $[7,21]$. This will have raised the overall awareness and expectations of their professional role profile in younger pharmacists.

In contrast to the high willingness to administer immunisations in general, this study emphasises a reluctance towards pharmacist-provided vaccination of vulnerable groups, i.e. children under 14 years $(15.6 \%$ willingness, $n=49)$ and adolescents from 14 to 17 years (55.4\% willingness, $n=174)$. These findings do not correspond to results from Marra, Kaczorowski and Marra (2010), who conducted a survey among staff pharmacists and pharmacy managers/ owners in British Columbia, Canada [22]. They reported that $46.3 \%(n=57)$ of respondents were willing to administer vaccines to children under 12 years old. However, the study does not indicate the representativeness of the small sample size and must therefore be interpreted with caution. Whilst safety reasons represent an important barrier to pharmacist-provided immunisation of vulnerable groups, reluctant pharmacists should be made aware of their important role in improving children's immunisation status. In 1997, Hoeben et al. already emphasised pharmacists' engagement in childhood immunisations in the USA, where this practice is still widely implemented [23]. Additionally, pharmacists who are generally unwilling to vaccinate showed higher probability to evaluate personnel resources, close patient contact and management of side effects as critical/highly critical. Hence, sufficient staffing and appropriate training to manage side effects, particularly anaphylactic reactions, can be seen as important aspects when attempting to gain further support in pharmacists not willing to immunise. While the probability of anaphylaxis is very low with an incidence of one per 100.000 to one per 1.000 .000 doses, it can be life threatening [24]. In line with other countries, where pharmacist-provided vaccination is already implemented, adequate training and standard operating procedures should be in place for Austrian pharmacists to safely manage side effects [25]. In contrast to side effects, acceptance by physicians and financial remuneration were generally rated as the least important requirements for service implementation. This finding may be the result of community pharmacists' strong attitude towards vaccine administration for the benefit of public health regardless of funding and acceptance which has been sparked by the current national debate and strong Austrian Medical Association opposition [10]. Nevertheless, for a community pharmacy service to be successfully implemented the awareness and acceptance of such an innovation is vital [26]. Pharmacists' strong attitude towards administration can also be reflected in their rating of the sight of blood and close patient contact as a non-concern. In terms of appropriate education, the majority of participating pharmacists considered the right time for training to be after the foundation training with a 2-yearly renewal, even though continued professional development is not mandatory for Austrian pharmacists up to now. This mirrors recommendations of the General Pharmaceutical Council in Great Britain. They direct the completion of the Declaration of Competence framework, a self-declaration by service-providers that they are service-ready, at least every two years [27]. Regarding appropriate education, participants generally rated practical training more relevant than theoretical topics. The Austrian Chamber of Pharmacists already offered theoretical and practical immunisation training in the beginning of 2021 with the aim of quickly offering a vaccination service in the wake of potential legalisation changes. This had to be suspended due to legal action and political pressure by the Austrian Medical Association. This matches the perception of one pharmacist who commented that "physicians and their stakeholders represent an insurmountable hurdle in Austria' in the open comments. However, after thorough legal review the training could be re-enacted and now represents an important foundation for future legalisation of this service.

This study serves as a valuable instrument for stakeholders attempting to implement a pharmacist provided immunisation-service by highlighting critical requirements and important barriers. For successful service implementation pharmacists themselves should advocate among patients and physicians to obtain sufficient acceptance and emphasise Austrian community pharmacists' high willingness to administer immunisations.

\section{Conclusion}

This study clearly demonstrates the strong willingness of community pharmacists in Austria to actively administer immunisations in the future. Overcoming critical requirements and barriers, such as sound legislative implementation, adequate liability insurance and appropriate training, will be the basis for successful implementation of this service. Stakeholders should undoubtedly acknowledge pharmacists as highly qualified healthcare professionals in the immunisation process in order to improve patients' access to immunisations and potentially increase vaccination coverage.

Acknowledgements The authors would like to thank the Associations of Employed Austrian Community Pharmacists VAAÖ and Forum Pharmazie, especially Karoline Sindelar, MSc, for their help in distributing the questionnaire. They further acknowledge all the participants for their contributions in this survey. 
Author contribution NL: conception and design, proposal writing, data acquisition and collection, data analysis, results interpretation, drafting the manuscript, final approval of the version to be published. MR: interpretation of data, revising the work, final approval of the version to be published. TM: interpretation of data, revising the work, final approval of the version to be published. AEW: conception and design, proposal and manuscript reviewing and proof reading, results interpretation, final approval of the version to be published

Funding The authors did not receive support from any organization for the submitted work.

Availability of data and material The datasets analysed during the current study are available from the corresponding author on reasonable request.

Conflict of interest The authors declare that they have no conflict of interest.

Ethics approval Ethical approval for the study was obtained by the School Research Ethics Committee of Robert Gordon University, Aberdeen on the $7^{\text {th }}$ December 2020. The Ethics Committee of the City of Vienna advised that no further ethical approval was needed.

Consent to participate Participating pharmacists were provided detailed information and assurance of anonymity in the invitation E-mail, the information leaflet and at the beginning of the questionnaire in line with the British Psychological Society's Ethics Guidelines for Internet-mediated Research. The returned completed questionnaire was taken as informed consent.

Open Access This article is licensed under a Creative Commons Attribution 4.0 International License, which permits use, sharing, adaptation, distribution and reproduction in any medium or format, as long as you give appropriate credit to the original author(s) and the source, provide a link to the Creative Commons licence, and indicate if changes were made. The images or other third party material in this article are included in the article's Creative Commons licence, unless indicated otherwise in a credit line to the material. If material is not included in the article's Creative Commons licence and your intended use is not permitted by statutory regulation or exceeds the permitted use, you will need to obtain permission directly from the copyright holder. To view a copy of this licence, visit http://creativecommons.org/licenses/by/4.0/.

\section{References}

1. World Health Organization. Immunization Coverage. 2017. https://www.who.int/news-room/fact-sheets/detail/immunizati on-coverage. Accessed 07.02.2021.

2. International Pharmaceutical Federation. An overview of current pharmacy impact on immunisation: A global report. 2016. https://www.fip.org/www/streamfile.php?filename $=$ fip/publications/FIP_report_on_Immunisation.pdf. Accessed 07.02.2021.

3. Pharmaceutical Group of the European Union. Access to Vaccination through Community Pharmacy. 2018. http://www. activecitizenship.net/files/patients_rights/active-citizens-ineurope-advocate-for-vaccination-training-seminar/de_BELIE_
Access_to_vaccination_through_community_pharmacy_JDB. pdf. Accessed 07.02.2021.

4. Baroy J, Chung D, Frisch R, et al. The impact of pharmacist immunization programs on adult immunization rates: a systematic review and meta-analysis. J Am Pharm Assoc. 2016;56:418-26.

5. Isenor JE, Edwards NT, Alia TA, et al. Impact of pharmacists as immunizers on vaccination rates: a systematic review and meta-analysis. Vaccine. 2016;34:5708-23.

6. Spinks J, Bettington E, Downes M, et al. Does policy change to allow pharmacist provision of influenza vaccination increase population uptake? A Syst Rev Aust Health Rev. 2020;44:582-9.

7. Österreichische Apothekerkammer. Apotheke in Zahlen 2021. 2021. https://www.apothekerkammer.at/fileadmin/Kommunikat ion/Jahresbericht2021_online_xl_01.pdf. Accessed 27.07.2021.

8. Bundesministerium für Soziales, Gesundheit, Pflege und Konsumentenschutz. Frühsommer-Meningoenzephalitis FSME. 2020. https://www.sozialministerium.at/Themen/Gesundheit/Ueber tragbare-Krankheiten/Infektionskrankheiten-A-Z/Frühsomm er-Meningoenzephalitis-(FSME).html. Accessed 26.03.2021.

9. Österreichischer Verband der Impfstoffhersteller. Influenza Errechnete Durchimpfungsrate Gesamtbevölkerung Österreich 2004-2019. 2020. https://oevih.at/wp-content/uploads/2019/ 05/impfverhalten_influenza_in_oesterreich_status_2019.pdf. Accessed 27.08.2020.

10. Österreichische Ärztekammer. Niemand Braucht Sinnlose Experimente Bei Corona-Impfung. 2021. https://www.aerzt ekammer.at/presseinformation/-/asset_publisher/presseinfo rmation/content/id/911327. Accessed 08.11.2021.

11. Parlament Republik Österreich. Entschließungsantrag 669/A(E) vom 17.06.2020 (XXVII. GP) - Impfen in der Apotheke. 2020. https://www.parlament.gv.at/PAKT/VHG/XXVII/A/A_00669/ index.shtml. Accessed 08.11.2021.

12. Mahase E. Vaccination uptake: access is still biggest barrier, experts warn. BMJ. 2019;15576.

13. McColl E, Jacoby A, Thomas L, et al. Design and use of questionnaires: a review of best practice applicable to surveys of health service staff and patients. Health Technol Assess. 2001. https://doi.org/10.3310/hta5310.

14. Atkins L, Francis J, Islam R, et al. A guide to using the theoretical domains framework of behaviour change to investigate implementation problems. Implement Sci. 2017;12:77.

15. Cane J, O'Connor D, Michie S. Validation of the theoretical domains framework for use in behaviour change and implementation research. Implement Sci IS. 2012;7:37.

16. The British Psychological Society. Ethics guidelines for internet-mediated research. 2021. https://www.bps.org.uk/sites/ www.bps.org.uk/files/Policy/Policy\%20-\%20Files/Ethics\% 20Guidelines\%20for\% 20Internet-mediated\%20Research.pdf. Accessed 07.08.2021.

17. Hagmair G, Amering M, Kaiser G, et al. Beratungstätigkeit von ApothekerInnen bei psychischen und kardiovaskulären Gesundheitsproblemen ihrer KundInnen. Ergebnisse einer Umfrage unter ApothekerInnen in österreichischen öffentlichen Apotheken. Neuropsychiatrie. 2014;28:178-84.

18. Deibl S, Mueller D, Kirchdorfer K, et al. Self-reported clinical pharmacy service provision in Austria: an analysis of both the community and hospital pharmacy sector-a national study. Int J Clin Pharm. 2020;42:1050-60.

19. Edwards N, Gorman Corsten E, Kiberd M, et al. Pharmacists as immunizers: a survey of community pharmacists' willingness to administer adult immunizations. Int $\mathrm{J}$ Clin Pharm. 2015;37:292-5. 
20. Toklu HZ, Hussain A. The changing face of pharmacy practice and the need for a new model of pharmacy education. J Young Pharm. 2013;5:38-40.

21. Nouri A, Hassali M, Hashmi F. Contribution of pharmacy education to pharmaceutical research and development: critical insights from educators. Perspect Public Health. 2020;140:62-6.

22. Marra F, Kaczorowski JA, Marra C. Assessing pharmacists' attitudes regarding delivery of the pandemic influenza vaccine in British Columbia. Can Pharm J Rev Pharm Can. 2010;143:278-84.

23. Hoeben BJ, Dennis MS, Bachman RL, et al. Role of the pharmacist in childhood immunizations. J Am Pharm Assoc. 1997;37:557-62.

24. Dreskin SC, Halsey NA, Kelso JM, et al. International Consensus (ICON): allergic reactions to vaccines. World Allergy Organ J. 2016;9:32.
25. Bushell M-JA, Ball PA. Managing vaccine-associated anaphylaxis in the pharmacy. J Pharm Pract Res. 2015;45:24-30.

26. Weir NM, Newham R, Dunlop E, et al. Factors influencing national implementation of innovations within community pharmacy: a systematic review applying the consolidated framework for implementation research. Implement Sci. 2019;14:21.

27. NHS Health Education England. Declaration of Competence for Vaccination Services. 2021. https://www.cppe.ac.uk/services/ docs/vaccination\%20services.pdf. Accessed 18.04.2021.

Publisher's Note Springer Nature remains neutral with regard to jurisdictional claims in published maps and institutional affiliations. 